\title{
BIOPODER E TÉCNICAS REPRODUTIVAS
}

\section{BIOPOWER AND REPRODUCTIVE TECHNIQUES}

\section{Ilze Zirbe| ${ }^{1}$}

Resumo: A história das técnicas reprodutivas evidencia o que Foucault chamou de fazer viver e deixar morrer como uma estratégia das práticas políticas modernas. A biotecnologia em funcionamento no campo da reprodução humana disponibilizou técnicas centradas na fabricação, controle e manutenção da vida. Este artigo defenderá que as tecnologias reprodutivas não foram desenvolvidas para resolver questões de infertilidade, como anunciavam, mas para controlar os processos reprodutivos do corpo da mulher e, com isso, chegar a controlar aspectos populacionais variados. O artigo divide-se em seis partes. A primeira apresentará a noção foucaultiano de biopolítica, apontando para a centralidade da reprodução humana nesse tipo de política. A segunda parte apresentará o caminho histórico percorrido pelas pesquisas no campo da reprodução humana e a ênfase dada ao corpo de mulheres como campo de experimentação. A manipulação das vidas das mulheres com fins biopolíticos (reprodutivos) será abordada em seguida, ilustrada pelas políticas nacionais de natalidade de períodos pós-guerra. Na quarta parte do artigo, o tema da inseminação artificial será apresentado como um projeto que teve dificuldades de implementação por conta do potencial imaginativo (e prático) para mulheres interessadas em constituir família sem a presença de um homem. A fertilização in vitro será apresentada, em seguida, como elucidativa da visão objetificante dos cientistas em relação às mulheres e de um projeto de controle da reprodução feminina. Por fim, questionar-se-á as intenções das pesquisas reprodutivas feitas em nome do tratamento da infertilidade, relacionandoas com as variadas causas de infertilidade e os interesses do mercado.

Palavras-chave: tecnologias reprodutivas; biopolítica; questões de gênero

\begin{abstract}
This article will argue that reproductive technologies were not developed to address infertility issues as they advertised, but to control the reproductive processes of woman's body and thereby control a variety of population aspects. The article is divided into six parts. The first one will present the Foucaultian notion of biopolitics, pointing to the centrality of human reproduction in it. The second part will present the historical path covered by research in the field of human reproduction and the emphasis given to the body of women as a field of experimentation. The manipulation of women's lives for biopolitical (reproductive) purposes will be then illustrated by national birth rate policies of a post-warperiods. In the fourth part of the article, the topic of artificial insemination will be presented as a a project that had difficulty implementing it because of its imaginative (and practical) potential for women interested in forming a family without a man. In vitro fertilization will be presented, then, as an elucidative of the objectifying vision and practice of scientists in relation to women and of a project to control female reproduction. Finally, we will question the intentions of the reproductive research done in the name of the treatment of infertility, relating them to the various causes of infertility and the interests of the market
\end{abstract}

\section{A CENTRALIDADE DA REPRODUÇÃO PARA A BIOPOLÍTICA}

${ }^{1}$ Universidade Federal de Santa Catarina. Orcid: http://orcid.org/0000-0001-6633-6525 
Durante o seu curso anual no College de France de 1975-1976², Foucault apresenta a tese de que a forma européia tradicional de poder político representada na figura de um monarca detentor do direito de fazer morrer e deixar viver, modificara-se no século XVIII. A nova forma, vigente na época moderna, preocupava-se com técnicas que possibilitassem fazer viver e deixar morrer, mediante um conjunto de medidas políticas centradas na fabricação, controle e manutenção da vida (FOUCAULT, 2005, p.287). O significativo aumento da população apresentara uma série de novas questões à prática governamental que passava a pensar nela como um problema a um só tempo cientifico e politico, como problema biologico e como problema de poder (2005, p. 293). $\mathrm{O}$ estudo e manejo dos seres humanos, enquanto especie, entrava em cena.

O controle dos mais diversos aspectos da vida humana passava a ser considerado necessário e possivel mediante o uso de tecnologias de poder centradas em dois campos diferentes e interligados entre si: o individual (centrado no corpo) e o coletivo (centrado na idéia de população). Tanto os macro-fenômenos da sociedade quanto os detalhes mais corriqueiros, pessoais, íntimos da vida de seus indivíduos entravam em foco.

Uma espécie de anatomo-politica foi implementada visando transformar os indivíduos em corpos e sujeitos funcionais (politicamente dóceis e economicamente úteis) ${ }^{3}$, entendidos como organismos dotados de capacidade produtiva. Tecnologias na forma de dispositivos ${ }^{4}$ disciplinares entraram em cena para adestrar esses sujeitos-corpos e produzir, igualmente, conhecimento sobre eles. Anotaç,óes meticulosas passaram a ser realizadas no campo da pedagogia, da medicina, da ação penal, da sexualidade etc., produzindo um poder-saber que serviria base para estabelecer verdades (morais, científicas, politicas...). O trinômio poder-saber-verdade, em uma relação de reforço recíproco entre si, passaria a definir o normal ou anormal, o correto ou incorreto, o bom ou mau para si (e para o Estado) (Foucault, 1987).

Os indivíduos, agrupados entre si, formavam, igualmente, um corpo-espécie (a população). Também esse corpo, ampliado e unificado, precisaria ser controlado por meio de técnicas que registrassem seus fenômenos, os quantificassem e implementassem formas de controle e otimização. As novas políticas governamentais passaram a ter o interesse e os meios de intervir na produção e reprodução de certos grupos (considerados desejáveis, bons e úteis) e na eliminação de outros (considerados indesejaveis, nocivos ou improdutivos).

Para Foucault, tais práticas configuravam um biopoder em funcionamento a favor de uma biopolítica.

O termo biopolítica não era, em verdade, algo novo. Segundo Roberto Esposito (2004), é possível encontrá-lo nos escritos só sueco Rudolph Kjellen, em 1930, para designar uma política de expansão considerada necessária aos estados modernos. O termo reapareceu na França, na década de 1960, designando uma política desejosa de levar em conta os poderes

2 Compilado e publicado posteriormente, sob o nome Il faut défendre la société e traduzido para o português (1999) como "Em Defesa da Sociedade". Neste trabalho, utilizou-se a 4a edição da obra (2005).

3 Uma das idéias centrais da obra Vigiar e Punir: o nascimento da Prisão (1975) que, juntamente com outros escritos e aulas da década de 1970 (Théories et Institutions Pénales, curso ministrado entre 1971-72; a Sociedade Punitiva, curso de 1972-73; o Poder Psiquiátrico, 1973-74; Os Anormais, 1974-75; História da Sexualidade, vol I: A vontade de saber, 1976), podem ser classificados como parte de uma História das Disciplinas Modernas.

4 Como observam Rabinow e Rose (2003), uma das ferramentas conceituais foucaultianas mais interessantes e eficazes é a do dispositivo: um mecanismo de poder cuja função é definir, normatizar e controlar determinados alvos (o corpo, a sexualidade, o matrimônio, estudantes, prisioneiros, etc.). Para aprofundar-se no assunto, ver o verbete "dispositivo" em Castro (2004). 
naturais da vida e sujeitá-los a valores civilizatórios, assim como no mundo anglo-saxão, no início da década de 1970, para descrever o comportamento político dos seres humanos a partir de conceitos biológicos (KECK, 2008). Foucault retomou o termo em "um esforço de reflexividade sobre uma tendência em curso de formação" (KERCK, 2008) e buscou entender o que exatamente estava sendo transformado na inteligibilidade das relações de poder aplicadas ao domínio geral da vida. 5

Do ponto de vista da Filosofia, a vida humana sempre foi alvo da política, uma vez que nós, seres humanos, somos seres que vivem em sociedade e, por conta disso, fazemos política e temos nossas vidas marcadas por ela. No entanto, a discussão apresentada por Foucault remete a algo diferente, a um tipo de política que também efetua uma despolitização ao reduzir homens e mulheres à sua capacidade funcional (que pode ser estudada, classificada, contabilizada, manipulada etc.), para "o bem geral" e a maximização da vida da população.

A biopolítica, no entendimento de Foucault, passa a abranger todos os fenômenos da vida humana ao aliar técnicas disciplinares a técnicas de regulação. Assim, saúde, higiene, reprodução, fecundidade, envelhecimento, raça, educação, segurança pública, acidentes de trabalho/trânsito, ecologia, organização urbana, etc., são assumidos como temas políticos de suma importância. A um só tempo, corpo e população são capturados em um campo político carregado de mecanismos de poder com a finalidade de otimizar-lhes a vida.

As reflexões de Foucault interligam-se com o estudo de temas diversos (como sexualidade, guerra, etc.) ${ }^{6}$. Nesse artigo, me interesso, em especial, pelo entrelaçamento entre controle populacional e reprodução humana. Mais especificamente, sobre as implicações desse controle sobre os corpos de mulheres. A temática diz respeito a questões de gênero, mas também à raça, classe e deficiência, bem como a questões econômicas, de saúde pública, de autonomia decisional e políticas globais. É possível dizer que a biopolítica visa controlar os seres humanos de forma gradual, em nome de um interesse coletivo, e o faz aplicando critérios bastante desiguais (de acordo com o valor e as qualidades atribuídas a grupos distintos) que podem resultar em mais desigualdade.

Para Foucault, a sexualidade era crucial, em parte por fazer a ligação entre a anátomo-política do corpo humano e a biopolítica da população. No entanto, para Robinow e Rose (2012), nos últimos 50 anos, esses dois problemas foram dissociados, uma vez que "a sexualidade foi parcialmente desvinculada do simbolismo e das práticas de reprodução, e a própria reprodução tornou-se o tema de uma série de formas de conhecimento, tecnologias e estratégias políticas que têm pouco a ver com sexualidade". Para esses pesquisadores, isso se deve por conta de um triplo movimento: a reprodução passou a ser problematizada por suas consequências econômicas, ecológicas e políticas (superpopulação, limites ao crescimento etc.), tanto a nível nacional como global; uma nova política de aborto está surgindo, assumindo diferentes formas em diferentes contextos nacionais; e, por fim, a questão da "escolha reprodutiva" para casais

5 Os textos nos quais a temática da biopolítica é apresentada são Em defesa da Sociedade (já citado), Segurança, Território e População (compilação das aulas ministradas durante o ano de 1977-78); O Nascimento da Biopolitica (aulas de 1978-79) e Do Governo dos vivos (aulas de 1979-80) e a História da Sexualidade, vol 1.

6 Segundo Farhi Neto (2008, p.48), poderíamos, inclusive, falar em cinco formulações distintas de Biopolítica, formulaçooes "que não são iguais entre si, mas também não são totalmente diferentes.... cada uma delas remetendo a um confronto da política com algum outro domínio, aparentemente, exterior a ela: política e saúde; política e guerra; política e sexualidade; política e segurança; finalmente, politica e economia." O confronto da política com estas áreas evidenciaria algumas das lutas existentes no campo social e a tentativa de domínio/controle/normalização destes campos. 
que não podem ter filhos caminha para definir a infertilidade como uma condição médica remediável. Podemos acrescentar um quarto movimento: o de casais homoafetivos que querem ter acesso às tecnologias reprodutivas. Todos esses elementos "se combinaram, embora de maneiras diferentes, para fazer da reprodução o espaço de um problema no qual uma rede de conexões aparece entre os indivíduos e o coletivo, o tecnológico e o político, o legal e o ético. É um espaço biopolítico por excelência." (ROBINOW e ROSE, 2012).

\section{A REPRODUÇÃO HUMANA E O CORPO DE MULHERES COMO CAMPO DE EXPERIMENTAÇÃO}

Geena Corea (1985), precursora de estudos feministas ligados ao campo das técnicas de reprodução humana (em especial à inseminação artificial e à fertilização in vitro), efetuou uma extensa pesquisa sobre o surgimento dessas técnicas nos EUA, Inglaterra e Austrália. Após inúmeras entrevistas com médicos e pesquisadores considerados pioneiros nesse campo, assim como leituras de material disponível na mídia, universidades e comitês de ética, Corea defendeu a tese de que tecnologias reprodutivas não têm a fertilidade como objetivo central, mas o controle da população e a exploração da mulher como meio de chegar a esse controle. Em seu livro Mothering Machine, ela evidencia a forte relação entre pesquisas para tratamento da infertilidade (ou de prevenção de doenças genéticas) e discursos classistas e eugênicos (racistas) que as acompanharam. De igual forma, ela aponta para a instrumentalização das mulheres e a omissão desses pesquisadores quanto aos riscos envolvidos, à complexidade dos procedimentos e sua natureza experimental.

Até poucas décadas atrás, os engenheiros reprodutivos eram todos homens e a grande maioria das pessoas cujos corpos foram utilizados para experimentos de alto risco era de mulheres. Trata-se de uma ciência desenvolvida de acordo com os valores e a visão de mundo de um pequeno grupo de homens brancos de classe média alta que viam a si mesmos como superiores e capazes de fornecer ao Estado ferramentas de controle populacional. O desejo de controle e dominação dos mais variados grupos (mulheres, imigrantes, negros, trabalhadores pobres etc.) é uma constante nas falas e práticas desses prestigiados "homens da ciência".7

Não por acaso, Corea faz inúmeras associações entre as fêmeas da espécie bovina e as fêmeas humanas. A visão objetificante dos pesquisadores e a certeza que tinham de que suas ações eram legítimas (legitimadas por seus pares) permitia-lhes manipular os corpos de ambas as espécies. O exemplo da inseminação artificial é o mais evidente, tendo saído dos currais dos fazendeiros diretamente para os consultórios médicos. De igual forma, discursos de "melhoramento da raça" e produção de "espécimes de melhor qualidade" aplicavam-se a ambos os casos e seguem em funcionamento nas técnicas de reprodução assistida contemporâneas, ainda que mediante o uso de um linguajar diferenciado.

Tanto no caso da inseminação artificial quanto da fertilização in vitro, é possível ver funcionando, simultaneamente, dois discursos distintos. No primeiro deles, ambas as técnicas são colocadas à disposição de uma classe social bem definida, branca e com um bom poder aquisitivo, para que possa se reproduzir. No segundo caso, as mesmas técnicas são invocadas para auxiliar no controle populacional dos grupos considerados indesejáveis.

No caso da inseminação artificial, acreditava-se que ela poderia servir aos propósitos de

7 Atualmente, a linguagem não evidencia mais, de maneira tão evidente, os interesses racistas, classistas e de dominação de gênero de parte dessas práticas, o que não significa, necessariamente, que elas deixaram de ter tais características.

PRACS: Revista Eletrônica de Humanidades do Curso de Ciências Sociais da UNIFAP https://periodicos.unifap.br/index.php/pracs ISSN 1984-4352 Macapá, v. 12, n. 1, p. 123-143, jan./jun. 2019 
melhoramento da raça por meio dos bancos de esperma. Tais bancos deveriam armazenar material biológico coletado dentre os homens considerados os mais inteligentes e saudáveis de cada nação8. Voltaremos a isso mais tarde. No momento, retorno a uma segunda associação feita por Corea entre as fêmeas da espécie bovina e da espécie humana: a produção de novos indivíduos para cada uma das espécies.

\section{A REPRODUÇÃO HUMANA COMO FUNÇÃO DA MULHER}

Ainda que, atualmente, a principal função de uma vaca seja vista como a da produção de leite (resultante da própria indústria do leite e seu marketing), a produção de bezerros sempre foi central (uma vez que serve tanto à formação do gado leiteiro quanto à indústria da carne). Ao longo de toda a história do ocidente, ainda que isso não apareça sempre de maneira explícita (o que poderia levar, inclusive, ao empoderamento das mulheres), quando a sociedade é controlada por um grupo de homens, a principal função social da mulher passa a ser a de produzir e criar filhos para gerar riqueza ou poderio bélico (na forma de novos trabalhadores e soldados). Isso é bastante evidente nas campanhas nacionais de repovoamento após momentos de declínio populacional, como é o caso de períodos de guerra, fome generalizada ou epidemias geradoras de mortandade generalizada.

Evoco aqui as organizações pró-natalidade criadas nos mais diversos países europeus após a I grande guerra européia do século XX. Tais organizações atuavam em nome do patriotismo e do militarismo utilizando-se de argumentos que atrelavam a questão demográfica ao poderio militar e à riqueza da nação, em um período de rivalidade entre os estados. Esse foi o caso da Aliança Nacional Contra o Despovoamento na França que, em 1920, sancionou uma lei proibindo qualquer tipo de propaganda contraceptiva e, em 1923, proibiu a importação de contraceptivos (THÉBAUD, 1985). ${ }^{9}$

Em 1927, uma entidade transnacional foi criada na Europa, o Comitê Internacional para a Vida e a Família (CIVF), que, apesar das diferenças entre seus integrantes sobre questões familiares, defendia políticas pró-natalidade. No ano de 1929, seus representantes se opuseram ao ensino da biologia nas escolas francesas por entenderem que ela serviria de ferramenta de propaganda para uma política ativa de contracepção ${ }^{10}$. De igual forma, ganharam legitimidade internacional pela luta contra o aborto e contra qualquer prática contraceptiva. No congresso

8 Comumente a decisão de quem eram esses homens cabia ao médico-pesquisador que, por sua vez, via a si mesmo como o supra-sumo da sociedade. Isso aparece, por exemplo, em uma pesquisa registrada em 1979 e referenciada por Corea. A pesquisa apontou para o fato de que "80\% dos médicos usou estudantes de medicina ou residentes de hospitais como vendedores de esperma na maioria ou todas as vezes.... [e que estes] foram identificados pelo New England Journal of Medicine como "um grupo seleto com presumivel saúde e inteligência acima da média" (COREA, 1985, p. 20).

9 Muitos grupos feministas consideram que a popularização do uso de contraceptivos (em especial da pílula contraceptiva) foi co-responsável pela chamada "liberação da mulher" na segunda metade do século XX, uma vez que possibilitou desvincular a prática sexual da procriação (ou do risco de engravidar). Apesar do uso de contraceptivos variados ter sido prática recorrente entre mulheres de diferentes camadas sociais e tempos históricos, o interesse da indústria farmacêutica em popularizar a pílula foi um forte aliado na sua disseminação e no enfrentamento ao discurso da cúria católica que se opunha ao uso de contraceptivos de qualquer tipo. Muitos problemas de saúde associados ao uso da pílula permanecem sem serem devidamente discutidos pela sociedade, assim como alternativas menos nocivas à contracepção. Como este não é o objetivo deste texto, resolvemos apenas apontar essas questões, sem explorá-las mais profundamente.

10 Uma política neo-malthusianista, como era conhecida na época (inspirada no trabalho do pastor e economista britânico Thomas Malthus). Desde 1927, a Associação Americana de Higiene Social havia feito doações à Liga das Nações (uma organização internacional, idealizada em 1919, em Versailles, pelos países vencedores da Primeira Guerra Mundial e que existiu até 1946) para que fosse introduzido o estudo da biologia entre jovens e adolescentes.

PRACS: Revista Eletrônica de Humanidades do Curso de Ciências Sociais da UNIFAP https://periodicos.unifap.br/index.php/pracs ISSN 1984-4352 Macapá, v. 12, n. 1, p. 123-143, jan./jun. 2019 
de 1933, em Paris, os delegados do Comitê manifestaram seu desejo de que cada país passasse a produzir dados demográficos que medissem o crescimento populacional (CAPUANO, 2012, p. 40).

O comitê permaneceu ativo até 1939 e seus congressos possibilitaram a circulação de ideias concernentes ao que hoje chamamos de lobby (ação organizada com o objetivo de interferir diretamente nas decisões do poder público, em especial do poder legislativo, em favor de causas defendidas por um grupo). Capuano (2012, p. 41) observa que as reuniões internacionais do comitê influenciaram fortemente os modos de ação de organizações pró-natalidade nos mais diversos países, ao exemplo da League of National Life. Dirigida pelo ginecologista John McCann, essa organização britânica adotou os métodos propagandistas do continente (com brochuras, conferências, lobby junto ao Parlamento etc.) para um projeto de lei contra a propaganda de produtos anticoncepcionais e a favor de uma censura da defesa do controle da natalidade.

No mesmo período, um antifeminismo crescente, tanto na Europa quanto na América, defendia que o feminismo provocava entre as jovens "uma rebelião contra a lei natural e contra as veneráveis sujeições da maternidade e da vida familiar" 11.

A criação das medalhas de honra para mulheres com uma grande prole em países como a Itália e a Alemanha no final da década de 1930 segue na mesma direção. A “cruz de honra das mães" (Ehrenkreuz der deutschen Mutter ou Mutterkreuz), instituída pelo governo nazista (1938), e a "medalha de honra para mães de famílias numerosas" (medaglia d'onore per le madri di famiglie numerose), do governo fascista italiano (1939), representavam uma espécie de versão feminina das medalhas que os soldados recebiam por serviços prestados à nação. No caso da Alemanha, a medalha podia ser de bronze, prata ou ouro, de acordo com a quantidade de filhos gerados (um mínimo quatro, seis ou oito, respectivamente) e fazia parte de uma política de retomada do crescimento populacional aliada a planos expansionistas (WEYRATHER, 1993). Na Itália a honraria destinava-se a mulheres com sete filhos vivos ou mais e deveria ser usada do lado esquerdo do peito em todas as festas nacionais, solenidades civis e funções públicas (IPSEN, 1996)12.

A noção de que a vida, exemplificada nas taxas de nascimento e no controle dos indivíduos nascidos dentro de um determinado território, é um tipo de mercadoria ou riqueza, havia se tornado recorrente no final do século XIX. Esse controle assumiu características não apenas quantitativas mas também qualitativas com o crescimento do movimento eugenista. $\mathrm{O}$ termo engenia, cunhado em $1883^{13}$, fazia alusão a crença de que a pessoa ou grupo considerado melhor ou mais inteligente do que outros deveria controlar as vidas e a reprodução dos grupos e pessoas vistas como inferiores. Assim, ao lado de políticas européias voltadas ao aumento da população, nos EUA o interesse voltava-se à diminuição dos grupos “indesejáveis".

Muito influente nos EUA até meados da década de 1930, o movimento eugenista possuía em suas fileiras alguns dos mais admirados estadistas, acadêmicos, cientistas, médicos e religiosos daquele país. Defendia frequentemente a esterilização de pessoas considerados por seus

11 "Nota sobre a Atividade do Comitê Internacional para a Vida e a Família nos Anos 1929-1930", Terceira Conferência para a Vida e a Família, agosto de 1930, p.7, apud: CAPUANO, 2012, p. 35.

12 É possivel visualizar essas medalhas nos sites: <http://arsmilitaris.altervista.org/faleristica/madre.html> e <https:/ / www.dhm.de/lemo/kapitel/ ns-regime/innenpolitik/ mutterkreuz.htmls>.

13 Pelo explorador britânico e cientista natural Francis Galton, influenciado pela teoria da seleção natural de Charles Darwin que observava a "sobrevivência do mais apto". Conforme o verbete do dicionário Britannica. Disponível em : <https://www.britannica.com/science/eugenics-genetics>. Acessado em: outubro de 2018. 
defensores como biologicamente defeituosas (deficientes físicos, alcoolatras, pessoas com doenças venéreas, desempregados, usuários de drogas, "fracos da cabeça”) e que, na sua grande maioria, eram imigrantes, pobres e negros.

Quando Hitler demonstrou ao mundo a aplicação em massa de suas políticas de eugenia e novos desenvolvimentos na antropologia e no campo da genética enfraqueceram as supostas bases científicas dela, muitos dos grupos que a defendiam dissolveram-se. No entanto, parte de seus integrantes aproximou-se dos grupos de controle populacional formados nas décadas de 1940 e 1950, com um vocabulário ligeiramente modificado, mas com as mesmas propostas: esterilizar os grupos tidos como inferiores ou problemáticos e investir na procriação das famílias brancas e abastadas.

Retomando o exemplo da coleta de esperma, citado anteriormente, a inteligência figurava entre os grupos que defendiam a esterilização de pobres e negros como algo próprio da raça branca. Este foi o caso de William Shockley, prêmio nobel em física, cujos escritos e entrevistas alertavam para o "perigo" do aumento de grupos tidos por ele como menos inteligentes (em especial, a população negra), capazes de causar uma queda na inteligência média dos EUA e levar ao declínio da civilização. Shockley acreditava, igualmente, que a miséria, assim como a inteligência, estava relacionada à genética (e não a causas sociais). ${ }^{14}$

Para evitar o aumento das parcelas indesejáveis da população e investir naquelas tidas como desejáveis, cientistas chegaram a propor, hipoteticamente, o uso massivo de produtos que causassem esterilidade. Seria uma maneira do governo gerenciar a nação, uma vez que poderiase dar "outro químico" à "pessoas licenciadas para gerar filhos", que revertesse a situação (COREA, 1985, p. 28). Schokley propôs, por exemplo, que todas as mulheres fossem temporariamente esterilizadas sendo a reversão possível somente para as que poderiam pagar pelo processo (o que criava um viés claramente classista e racista). Uma vez tendo parido a criança, um novo medicamento esterilizante deveria ser ministrado à jovem mãe, uma vez que o nível de saúde e inteligência do bebê deveriam ser observados antes de que uma segunda gestação fosse autorizada (COREA, 1985, p. 29).

Apesar do ideal de controle eugênico ainda figurar entre certos grupos de pesquisadores estadunidenses na década de 1970, a regra geral seguia sendo a da valorização da mulher como reprodutora da espécie. Nesse sentido, a reportagem publicada em um jornal peronista argentino (Las Bases) e republicada no New York Times, em 17 de março de1974, é bastante clara. Nela é afirmado que "nós temos de partir da base de que o principal trabalho de uma mulher é ter filhos".15

No título da reportagem citada acima é possível perceber seu caráter biopolítico e o papel central das mulheres nesse projeto: "A Argentina, esperando dobrar sua população neste século, está tomando medidas no sentido de restringir o controle [das mulheres] sobre a

14 Como fica claro em uma entrevista dada por ele na década de 1970 e disponível atualmente em vídeo. Nas suas palavras: "Minha pesquisa me leva inevitavelmente à opinião de que a principal causa dos déficits intelectual e social do negro americano é hereditária e racialmente genética na origem e, portanto, não é remediável em grande parte por melhorias práticas no meio ambiente" (Firing Line with William F. Buckley, Jr. Episódio S0145, Shockley's Thesis, Gravado em 10 de junho de 1974, publicado no youtube em 27 de janeiro de 2017. Fala encontrada aos 52:06 min. Da gravação. Disponível em: < https://www.youtube.com/ watch?v=7JOIqkh2ms8\&t=3116>.

$15 \mathrm{Na}$ história da Filosofia, por sua vez, também é possível encontrar, repetidas vezes, "grandes homens" defendendo que o lugar das mulheres é o doméstico porque a procriação e o cuidado de crianças é a sua função primordial. Ex: John Locke e Immanuel Kant. Ver: ZIRBEL, Ilze. O lugar da mulher na antropologia pragmática de Kant (Kant e-pints, Campinas, Série 2, v. 6, n. 1, p. 50-68, 2011) e "O problema do padrão duplo de cidadania das teorias políticas modernas" (XVII Encontro ANPOF, 2017, Aracajú. Coleção Encontro ANPOF, 2017, p. 106-127), ambos disponíveis on-line. 
natalidade". Poucos anos depois, o New York Times publicava o depoimento do ministro francês Michael Debré (06 de junho de 1978) que defendia não ser possível para a França "alcançar grandeza nacional a menos que ela duplique sua população". Por conta desse projeto, ele defendia "que as mulheres não devam ser autorizadas a usar contraceptivos e a abortar" e para persuadi-las a produzirem três ou mais crianças, o ministro propunha um programa de bônus, licenças-maternidade e outras vantagens em forma de diminuição de impostos. (KANDELL, 1974 e 1978 apud COREA, 1985, p.14).

\section{INSEMIAÇÃO ARTIFICIAL COMO UM PERIGO À FAMÍLIA}

Aqui volto mais uma vez à temática da inseminação artificial. O estudo dos discursos ligados à sua implementação em humanos evidencia variadas técnicas de controle das vidas e corpos das mulheres em meio às negociações de homens brancos que queriam fazer avançar novas técnicas reprodutivas sem perder seu poder sobre as mulheres.

Apesar da inseminação artificial ter sido possível desde a década de 1930, sua prática se deu a passos lentos. O fato de poder ser utilizada em programas de "melhoramento humano" não foi o suficiente para popularizá-la. Pelo contrário, a possibilidade de sua popularização alarmou os homens de diversas classes mediante a possibilidade do esperma do marido não precisar mais ser usado para inseminar sua esposa. Outro homem poderia fazê-lo, e melhor.

Os bancos de esperma representavam uma ameaça à família patriarcal e à dominação masculina por abrirem uma brecha no imaginário das mulheres à formação de famílias sem maridos. Por séculos às mulheres era requerido que gerassem apenas crianças "legítimas", ou seja, geradas dentro da instituição do matrimônio. Assim era garantido ao homem que "possuía uma mulher" que os filhos dela gerados eram seus. O conceito de "legitimidade", como observou Corea (1985, p.38), é, ao menos nesse contexto, um conceito inventado por homens para homens com a função de controlar mulheres que queiram desafiar as regras por eles impostas à reprodução. Apoiados nesse conceito, homens podiam punir tanto as mulheres que quebravam suas regras quanto as crianças por elas geradas fora do casamento. Uma mulher não possui o poder de "tornar legítimo" um filho ou filha por ela gestado.

Contrariando os desejos de cientistas pró inseminação artificial, as cortes da Inglaterra, Canada, EUA, Itália e Alemanha legislaram no sentido de tornar essa prática equivalente ao adultério (para as mulheres, obviamente), no caso do esperma utilizado não ser o do marido. Ela também podia ser motivo para divórcio e possível condenação judicial, não importando se o esposo havia consentido ou não com a prática (MASSEY JR, 1963, p. 79).

Apesar dos discursos que associavam a função política e social da mulher à maternidade ou que atribuíam a toda mulher um desejo irresistível de ser mãe, esperava-se das esposas com maridos inférteis que permanecesse sem filhos. Ainda assim, diante da simplicidade da técnica, mulheres casadas também recorriam a ela para conceber e, muitas vezes, driblavam os consultórios médicos (e os maridos?). Essa prática explica a recomendação do comité da sociedade americana de fertilidade, em 1980, para que multas e prisões fossem aplicados a pessoas de fora da classe médica que praticavam inseminação artificial (COREA, 1985, p. 42).

Uma reportagem do jornal Chicago Tribune, de dezembro de 1985, afirmava: "Infelizmente, o bom esperma é mais difícil de encontrar do que costumava ser". Podemos nos questionar sobre as intenções dessa reportagem ou sobre o que quer dizer com "bom esperma". Contudo, ela aponta para a diminuição da fertilidade masculina por conta de uma série de 
fatores (caxumba, varicela, tabagismo, poluição ambiental etc.) e para o fato de que pouco estava sendo feito para tratá-la (ANDERSON, 1985).

Voltado novamente um pouco no tempo, no final da década de 1970, em plena revolução sexual. O número de mulheres interessadas em permanecer solteiras aumentava nos EUA e no mundo. Com a pressão de grupos feministas organizados, a inseminação artificial em mulheres “sem maridos" passou a ser possível. Lésbicas ou não, muitas eram virgens (apelidadas, inclusive, de virgens marias) sem interesse na relação sexual com um homem, mas interessadas em ter um filho.

O fenômeno gerou uma contra-reação por parte da jurisprudência masculina que passou a legislar a favor dos doadores de esperma em questões de paternidade. Para a mulher casada, o doador deveria permanecer anônimo afim de assegurar os direitos do marido. Nesses casos, a paternidade não residia no esperma. No entanto, quando a mulher não era casada, a paternidade voltava a ser fixada no fluído seminal e abria-se mão da regra estipulada para o anonimato do sêmen (COREA, 1985, p. 51). De um dia para o outro, a mulher poderia vir surgir no seu horizonte um homem reivindicando o direitos sobre a criança .

\section{FERTILIZAÇÃO IN VITRO}

Se pouco interesse havia para enfrentar questões de infertilidade masculina, o mesmo não pode ser dito para a chamada infertilidade feminina e todos os procedimentos investigativos desencadeados sobre o corpo da mulher em nome do seu "tratamento".

Em 1976, quando a equipe dos irmãos Richard e Randolph Sees cogitou começar a fazer em mulheres os experimentos feitos em vacas (sim, mais uma vez as vacas!) deram a eles o nome de "tratamento da infertilidade". O procedimento realizado na espécie bovina, no entanto, visava a comercialização de embriões gerados em "vacas premiadas" para o útero de "vacas comuns". Richard Seed havia sido co-fundador, no início dessa mesma década, de uma empresa que comercializava o procedimento.

Objeções éticas surgiram por conta dos riscos envolvidos na retirada e reimplantação das células reprodutivas femininas (óvulos) em mulheres. Os irmãos Seed, no entanto, abriram uma clínica particular (a Reproduction and Fertility Clinic Inc.) no que foi por muito tempo o maior arranha-céus do mundo, o Water Tower Place, na cidade de Chicago. A propaganda (a alma do negócio!) vendia o procedimento como se fosse uma tecnologia segura e pronta a ser usada em mulheres. No entanto, tratava-se de algo experimental e por vários anos os irmãos não conseguiram levar à cabo nenhuma gravidez (COREA, 1985, p. 83).

A fertilização das células reprodutivas femininas (óvulos) fora do corpo da mulher é um procedimento complexo. Para chegar a desenvolvê-lo foi preciso desmembrar e dividir em vários passos o que ocorria no corpo feminino, submetendo cada um a intervenção e manipulação. Como observa Arditti (1997, p. 322), "cada um [desses passos foi] submetido a princípios eugênicos de seleção e eliminação. As tecnologias separam não apenas a procriação da sexualidade, mas mais significativamente, elas separam a maternidade em diferentes componentes."

As tecnologias reprodutivas obtiveram um elevado grau de aceitação social por conta das imagens positivas veiculadas pela mídia, alimentada por uma crescente indústria e pelos cientistas que trabalham na área (ARDIT'TI, 1997, p. 323). O foco, mais uma vez, são homens e mulheres brancos com alto poder aquisitivo. 
Os riscos e mesmo o grau de experimentação das técnicas costumaram, e em grande parte seguem sendo, omitidos. Em geral, o corpo das mulheres utilizado para o processo precisa ser testado intensivamente e submetido a repetidas manipulações intervencionistas. Cada um dos passos representando algum tipo de risco físico ou psicológico à saúde da mulher, havendo, inclusive, evidências crescentes de que os "tratamentos" hormonais usados aumentam os riscos de câncer nos ovários (ARDIT'TI, 1997, p. 323).

A primeira fase do processo da fertilização in vitro inclui a coleta de células reprodutoras femininas (óvulos). Os pesquisadores que pretendiam implementar esse método falavam dele de maneira muito semelhante ao da inseminação artificial. No entanto, a maneira de obtenção do material era muito distinta. Enquanto a coleta de esperma resulta de um processo simples de masturbação, é por meio de uma série de ações médicas, com consequências muitas vezes indesejadas sobre a saúde e o corpo da mulher, que os óvulos são "coletados".

No caso da clínica dos irmãos Seed, a primeira tentativa de captar óvulos se deu por meio de anúncios em jornais de pequeno porte (voltados para o púbico de cidades menores e periféricas) sob o título "ajude uma mulher infértil a ter um bebe" (ainda que muitas das mulheres não fossem inférteis). Segundo Corea (1985, p. 85), inicialmente apareceram 380 mulheres. Destas, 46 foram eliminadas por morarem muito longe e terem suas análises psicológicas rejeitadas. Do ponto de vista dos psicólogos contratados para avaliar o perfil dessas mulheres, apenas um terço das mulheres possuía a postura desejada (altruísta, de abdicação total). Mais da metade possuía um histórico de pais abusivos ou alcóolatras (foram eliminadas por medo do material genético delas?). Por fim, restaram apenas 27. O método do anúncio em jornal não surtiu os resultados desejados.

O segundo método demonstrou ser mais eficaz. A mulher considerada infértil deveria encontrar sua própria doadora de células reprodutivas: uma irmã, uma amiga, com quem tinha laço afetivos e que se submeteria mais facilmente aos longos meses de experimentação. Assim,

Ela sabe que só será aceita no programa de transferência de embriões se ela levar duas doadoras (...). Ela pede à sua melhor amiga e à sua irmã para fazerem isso por ela. Elas não querem, mas sabem como ela sofre. Se elas recusarem, pensarão estar negando à ela uma criança. Ela sente/pensa dessa maneira também. Ficará com raiva delas e não com a indústria de transferência de embriões. Assim, sentindo-se violadas, a amiga e a irmã da mulher deitam-se nas mesas dos ginecologistas, com as pernas nos estribos, e deixam os doutores as inseminarem artificialmente e mais tarde sugar os embriões para fora dos corpos delas. (COREA, 1985, p. 86)

Um terceiro método de retirada de óvulos acontecia nos consultórios ginecológicos, muitas vezes, sem o consentimento ou a informação sobre o que estava sendo feito. Corea observa que, nesses casos, chegou a ler centenas de relatórios e a maioria é estranhamente silenciosos sobre a natureza das doadoras de óvulos ou sob a compreensão delas sobre o que era feito com eles ou sobre haver ou não o consentimento da mulher. Muitos parecem ter sido roubados: mulheres passando por exames de laparoscopia (como parte de um exame de infertilidade ou de esterilização), por histerectomia (por fibroide uterina ou doenças pré-malignas), operadas por endometriose ou ovários policísticos etc., tiveram seus óvulos retirados sem consentimento. Nunca tinha-se óvulos suficientes e novos médicos precisavam se convencidos a aderir a causa da fertilização in vitro. (COREA, 1985, p. 103-105).

Ainda que as mulheres nasçam com uma certa quantidade de ovócitos (células germinativas reprodutivas), o amadurecimento de cada uma dessas células ocorre de maneira lenta. Para 
conseguir a maior quantidade possível de óvulos maduros por intervenção, cientistas desenvolveram a técnica da hiper-estimulação hormonal. Mediante o uso de altas doses de hormônios é possível forçar os folículos (programados pela natureza a amadurecer e liberar apenas um óvulo por mês) a utilizarem seu estoque de ovócitos (destinado a ser usado ao longo de toda a fase adulta de uma mulher), liberando e amadurecendo vários óvulos de uma única vez (encurtando, assim, a vida fertil da mulher). O procedimento possui riscos e efeitos colaterais penosos que podem ser ainda mais graves quando ocorrem gestações multi-gemelares. (CORREA; LOYOLA, 2015, p.758-759).

A hiper-estimulação pode resultar na captação de até 40 ou 50 óvulos em um único procedimento (imaginemos como fica o tamanho do ovário!) e é um processo que exige a aplicação diária de injeções de hormônios. Em seguida, os óvulos são aspirados de dentro do corpo para serem fecundados em uma placa de vidro (placa de petri). Alguns desses hormônios, atualmente, são recombinantes (obtidos por técnicas que utilizam ratas para a produção de um hormônio humano) e como observa Ana Reis (2012), "a porcentagem de pureza desses hormônios nunca é 100\%".

Juntamente com a técnica de remoção dos óvulos, passou-se à experimentação desses óvulos para inseminá-los. Suspeitava-se, no entanto, que o esperma humano, como ocorria em outras espécies, precisava ser "capacitado" ou condicionado em algum líquido (algo que normalmente ocorre no trato genital feminino) para vir a adquirir a habilidade de penetrar o óvulo. Enquanto esse processo não era elucidado, o mais "simples" era obter óvulos já fecundados para seguir com os experimentos. Mais uma vez, as mulheres utilizadas com esta finalidade não eram informadas sobre sobre todos os detalhes do que era realizado em seus corpos, sendo tratadas como objetos e não como seres dotados de razão, moralidade e sentimentos. Um exemplo disso pode ser encontrado no relato das práticas cirúrgicas do ginecologista John Rock e do patologista Arthur T. Hertig.

Rock e Hertig atuaram no Free Hospital for Women, de Massachussets. O hospital oferecia tratamento gratuito para mulheres pobres e, dentre elas, mulheres indicadas para histerectomia (remoção do útero) ou retirada dos ovários. Por indicação da equipe dos pesquisadores, essas mulheres passaram meses registrando diariamente a própria temperatura e levando esse registro ao hospital para a criação de um gráfico do ciclo de ovulação. De igual forma, foram instruídas a não utilizar nenhum método contraceptivo no mês que antecedia a cirurgia. Assim, tornava-se possível encontrar um embrião durante o procedimento cirúrgico (MCLAUCHLIN, 1983, p. 75).

Entre 1938 e 1954, um total de 34 embriões foi removido de 211 mulheres em fase inicial de gestação, no Free Hospital. A maioria dessas mulheres era católica. Muitas vezes, tinha-se medo de que tivessem um resfriado e não pudessem fazer a cirurgia. Nessa situação, poderiam descobrir que estavam grávidas e não aceitariam mais o procedimento por entenderem que se tratava de um aborto e um pecado (MCLAUCHLIN, 1983, p. 75). A equipe não parecia se preocupar com o fato dessas mulheres, encaminhadas para esse tipo de cirurgia, caso tivessem de enfrentar uma gravidez ela seria indesejada, de alto risco e em condições econômicas precárias.

Inúmeras vezes, quando os pesquisadores/médicos falavam aos seus clientes-pacientes sobre doação, transferência ou banco de óvulos, o que eles realmente estavam fazendo era uma doação e transferência de embriões. A escolha dos termos não era uma simples questão de linguagem ou falta de exatidão. Eles, na verdade, estavam cientes dos problemas que poderiam 
enfrentar caso utilizassem os termos corretos (com o público, com os clientes, com os investidores, com o governo).

O primeiro embrião fertilizado fora do corpo humano e a sobreviver ao processo de reimplantação no corpo de uma mulher, veio ao mundo em 1978, após nove anos de registros de tentativas sem sucesso (STEPTOE; EDWARDS, 1976). Não há, de fato, registros que permitam saber a quantidade de embriões utilizados nos diversos grupos de pesquisa ao longo desse tempo (e nem depois). É interessante observar, igualmente, que as primeiras mulheres anunciadas ao mundo como tendo concebido seus bebês por fertilização in vitro, tanto na Inglaterra quanto nos Estados Unidos, não estavam completamente a par da natureza experimental dos programas nos quais estavam envolvidos. Tanto o casal britânico (pais de Louise Brown), quanto o casal estadunidense (pais de Elizabeth Carr) manifestaram espanto ao saberem que eram os primeiros (COREA, 1985, p.167-168). Todos haviam sido levados a crer que a prática era comum e corriqueira (ou seja: segura).

Apesar do grande alarde na mídia com os primeiros "bebês de proveta", a técnica continuou sendo bastante falha. Em 1980, Apenas três dentre as 278 mulheres que participaram dos programas de "tratamento para infertilidade" tiveram filhos (um "sucesso" de 0,4\%). Quatro anos depois, um pouco mais de uma centena de Clínicas foram implementadas em inúmeros países do eixo Norte, além da Austrália, Israel e Japão. Todas juntas conseguiram apenas 200 bebês e, ainda assim, é possível desconfiar que algumas gestações tenham ocorrido de forma natural, a exemplo da primeira mulher supostamente estéril a engravidar na clínica Norfolk e engravidou enquanto esperava ser aceita para os procedimentos (COREA, 1985, p. 120).

Não raro, técnicas de fertilização in vitro são utilizadas em mulheres férteis para que seus maridos inférteis possam vir a ter filhos. Essas mulheres submetem-se a repetidas anestesias gerais e cirurgias, injeções diárias de hormônios ao longo de meses ou anos, correm risco de infecção, aborto, reação indesejada e desconhecida às drogas experimentais, cirurgia em caso de gestação ectópica (em algum lugar fora do útero)16, danificação ou perda da fertilidade e a própria morte. Trata-se de um processo que tem muitos riscos e muitas falhas. As estatísticas são muito precárias e muitas vezes não são verdadeiras.

Porque mulheres submetem-se a procedimentos perigosos e nocivos como a fertilização in vitro? A resposta a essa pergunta é complexa e não é objetivo deste artigo explorá-la. No entanto, podemos citar a pressão social exercida sobre uma mulher em uma cultura que lhe atribui como principal função e valor a maternidade (a produção de filhos). Além dos sentimentos de inferioridade cada vez crescentes em relação ao que é considerado "material genético desejável".

A questão eugênica, apesar de ter se modificado na linguagem, seguiu funcionando em meio aos planos de pesquisadores ligados à fertilização in vitro. Em 1984, o professor Carl Wood, do Queen Victoria Medical Center (Melbourne, Austrália), local onde ocorrera a primeira fertilização in vidro (mas que não conseguiu manter o embrião vivo durante seu processo de implante), anunciou que sua equipe estava discutindo o melhoramento genético por meio da seleção de esperma e óvulos. A questão racial ou de classe não aparece em sua fala, mas a "produção de crianças" dar-se-ia segundo as características desejadas pelos pais. Como podemos imaginar que o público alvo continuava sendo o mesmo (pessoas brancas com poder aquisitivo suficiente para bancar esse tipo de "produção"), é possível deduzir que esse melhoramento ficaria

16 Esta parece ser uma característica da espécie humana. É raramente diagnosticado em animais (nem mesmo em vacas, sendo aqui irônica no comentário) o que deixa clara a diferença entre métodos aplicáveis a uma espécie e outra.

PRACS: Revista Eletrônica de Humanidades do Curso de Ciências Sociais da UNIFAP https://periodicos.unifap.br/index.php/pracs ISSN 1984-4352 Macapá, v. 12, n. 1, p. 123-143, jan./jun. 2019 
restrito a esse grupo.

O Dr. Wood dava a entender que havia uma demanda de casais insatisfeitos com alguma característica pessoal. Por essa razão, interessavam-se em adquirir óvulos (e não esperma!) que viessem a atender suas expectativas. Os principais requisitos seriam a capacidade intelectual e a aparência (os equivalentes à inteligência e saúde, defendidos pelos eugenistas de décadas anteriores?!) (COREA, 1985, p. 126).

Novamente, é de se perguntar se as mulheres envolvidas nessas demandas tinham suficiente informação quanto aos procedimentos e riscos envolvidos. Em geral, o custo físico da produção de humanos in vitro recai sobre as mulheres, mas os pesquisadores sempre a apresentam como uma "dádiva", "terapia” ou "ação preventiva" contra certos defeitos.

\section{A QUESTÃO SELETIVA DO TRATAMENTO CONTRA INFERTILIDADE OU : INFERTILIDADE E MERCADO}

Embora as tecnologias reprodutivas tenham ajudado algumas mulheres (e homens) a terem filhos, elas também desviaram a atenção de causas de infertilidade induzidas por produtos químicos e medicamentos (HYNES, 1989, p.211). Assim, ao invés de enfrentarem a temática da infertilidade de uma maneira mais ampla, as pesquisas focaram no controle da reprodução humana e nos corpos das mulheres. Como resultado, estruturaram um novo campo de experimentação e engenharia genética. Trataremos dessas questões nessa parte do texto.

Historicamente, a reprodução é pensada como algo muito mais ao encargo de mulheres do que de homens e, em geral, quando um casal não tem filhos a suspeita de infertilidade sempre recai primeiro sobre a mulher. De igual forma, o efeito de certas substâncias químicas costuma ser avaliado levando em consideração o feto (a exposição da mulher em processo de gestação e os riscos de defeitos congênitos na criança). Além disso, a "rota do efeito" é pensada apenas através da mulher (os homens comumente não são incluídos na avaliação). Como observa Sexton,

Ao não considerar a reprodução humana como um continuum mais amplo, no qual os homens, assim como as mulheres, desempenham um papel, os perigos que as substâncias representam para a saúde reprodutiva dos homens e para o feto através dos homens têm sido sistematicamente ignorados." (SEXTON, 1993)

Scott (1984, p. 184) segue na mesma linha e pontua que "se a pesquisa científica revela que a saúde reprodutiva de uma mulher está em risco pela exposição ocupacional a uma substância em particular, não há justificativa científica para concluir que um colega [homem] não corre risco semelhante".

A disfunção, a falta ou uma baixa contagem de espermatozóides é uma das grandes causas de infertilidade em casais (MASON, 1993). Isso pode advir de uma condição genética préexistente, por conta do uso de drogas (dentre ela o álcool e o tabaco), de algumas doenças específicas (infecções, caxumba durante a puberdade), distúrbios hormonais e exposição à radiação e certos produtos químicos (incluindo toxinas ambientais, como a fumaça do cigarro).

Existem numerosas substâncias químicas associadas à infertilidade, tanto de homens quanto de mulheres. Um exemplo é o Bisfenol A (BPA), usado há décadas como componente de embalagens de plástico e garrafas d'água. Pesquisadores descobriram que o BPA perturba 
o sistema endócrino. Sua presença no corpo humano pode alterar o início da puberdade, causar abortos e diminuir a quantidade de espermatozóides (QUEEN's, 2003). Mulheres com concentrações mais elevadas de BPA apresentaram picos mais baixos de estradiol (um hormônio produzido pelos ovários que atua na função reprodutiva, pele, vasos sanguíneos, ossos e cérebro, por exemplo).

Pesticidas como o lindano (usado em seres humanos para tratar sarna e piolhos) interagem com o espermatozóide e afetam sua bi-camada lipídica, inibindo a resposta do esperma aos hormônios femininos presentes no útero e necessária à fertilização do óvulo. (NICOLOPOULOS e STAMATI, 2002). Outro pesticida, o pentaclorofenol, deixou de ser comercializado para o público, mas seu uso industrial persiste (como conservante de madeira para postes, estacas etc.). Segue sendo encontrado no ar, na água e no solo, podendo causar diminuição da função ovariana e, consequentemente, infertilidade.

Algumas profissões e ambientes de trabalho nos quais há uma ampla maioria masculina (indústria automobilística, metalurgia e mecânica) fazem uso frequente de tricloroetileno (TCE), um produto químico volátil utilizado como desengordurante (encontrado também em adesivos, lubrificantes, tintas, vernizes, pesticidas, removedores de manchas e fluidos de limpeza de tapetes). O TCE foi encontrado no fluido seminal de homens expostos a ele no ambiente de trabalho e é associado à infertilidade masculina (e a danos no fígado, rins e pulmões). Por fazer parte de produtos de limpeza, tem sido detectado em fontes de água subterrâneas e superficiais (QUEEN's, 2003).

Um grupo particular de substâncias químicas, chamadas de desreguladores endócrinos, conhecidos como EDCs, pode afetar a qualidade dos espermatozóides, óvulos e embriões. Dentre eles estão as dioxinas, os bifenóis policlorados (PCBs), o bisfenol A (BPA, citado acima), os hidrocarbonetos clorados, os compostos perfluorados (PFCs), os ftalatos etc..

Os PCBs diminuem a fertilidade baixando os níveis de progesterona e alterando o estrogênio e o ciclo ovulatório. Atualmente proibidos, foram usados em equipamentos elétricos, plastificantes e adesivos. Contaminaram nossos peixes, carnes e laticínios. Os hidrocarbonetos clorados são um grupo de produtos químicos que inclui pesticidas como o DDT e solventes como o clorofórmio. Sabe-se que alteram o eixo hipotálamo-hipófise-ovariano, alteram o estrogênio e a progesterona em uma mulher e afetam diretamente o óvulo de maturação do ovário (SEXTON,1993). Os PFCs (como o Perfluorooctanossulfonato - PFOS e o perfluorooctanoato - PFOA), são usados em roupas, espumas de combate a incêndios, carpetes, móveis e produtos de higiene pessoal. Também já contaminaram o solo, a água e o ar, acumulando-se na cadeia alimentar. Os ftalatos, por sua vez, são produtos químicos encontrados em recipientes e embalagens plásticas para alimentos e bebidas. Altos níveis desse químico no sangue pode causar endometriose (REDDY, et al., 2006).

Como observa Sexton (1993), substâncias que representam risco para a saúde reprodutiva geralmente estão atreladas a outros riscos.

A exposição crônica ao chumbo, por exemplo, pode danificar os sistemas sanguíneo, nervoso e urinário, possivelmente causando doença renal fatal, além de resultar em aborto espontâneo e defeitos congênitos por exposição masculina ou feminina; cádmio e cloreto de vinila são carcinogênicos para os quais não há nível seguro conhecido de exposição ocupacional, além de causar danos reprodutivos." (SEXTON,1993) ${ }^{17}$

17 O cloreto de vinila também é conhecido como cloroetano e é utilizado na produção de plástico, PVC. Estudos mostram

PRACS: Revista Eletrônica de Humanidades do Curso de Ciências Sociais da UNIFAP https://periodicos.unifap.br/index.php/pracs ISSN 1984-4352 Macapá, v. 12, n. 1, p. 123-143, jan./jun. 2019 
Por fim, Corea (1985, p. 147) aponta para procedimentos médicos que podem ser associados à perda da fertilidade, como infecção ou inflamação pélvica causada por implantação de dispositivos intra-uterinos (DIU) ou cesárias levadas a cabo por razões questionáveis; uso da pílula ou do contraceptivo injetável depo-provera; tratamentos reprodutivos de anormalidades induzidas pelo estrogênio sintético diethylstilbestrol (DES, também conhecido como stilbestrol) dentre outros. Podemos acrescentar, ainda, um procedimento médico que teria a função de prevenir certas doenças capazes de causar infertilidade. Médicos sabem, por exemplo, que o uso de preservativos previne doenças venéreas e que estas têm consequência sobre a fertilidade. A informação, no entanto, nem sempre é partilhada com as mulheres por conta de uma cultura que prefere mantê-las pouco informadas em questões de sexualidade, principalmente se são jovens.

Andrews (1999) observa que, antes da década de 1960 e do desenvolvimento da pílula, o preservativo e o diafragma protegiam contra doenças sexualmente transmissíveis e variadas formas de infecção vaginal. Determinados grupos faziam uso desses métodos. No entanto, a desinformação (recomendada para as mulheres, visando o cerceamento de sua sexualidade) impedia seu uso em massa. Aqui não é preciso comentar os motivos pelos quais a pílula "explodiu" como método contraceptivo, apesar de todos os riscos que sempre envolveu (e segue envolvendo). O lucro da indústria farmacêutica com um produto utilizado diariamente por milhões de mulheres é quase inimaginável.

Não por último, um novo fator pode ser acrescentado às causas de aumento de infertilidade entre homens e mulheres: a obesidade. Pesquisas realizadas em várias partes do mundo têm apontado para a correlação entre o aumento do índice de massa corporal e a diminuição da qualidade seminal e ovariana. Além de dificultar a fecundação, o sobrepeso apresenta maior risco materno-fetal durante todos os períodos da gestação (MORAES e ANDRADE, s/d). A obesidade está relacionada a certos tipos de alimentos (e não apenas aos chamados "hábitos alimentares", expressão que joga sobre os sujeitos a responsabilidade sobre o que comem) e a certo tipo de vida disponível (sedentária, circunscrita a pequenas áreas de circulação, a pouco lazer e atividade física), típicas de grandes centros urbanos.

Retomando a questão das políticas preventivas de proteção ao feto aplicadas aos ambientes de trabalho das mulheres. Draper (1993, p.101) observa que elas "contribuem para uma falsa crença de que os homens são capazes de resistir a exposições químicas tóxicas normalmente e com segurança". Além da implicação óbvia sobre a saúde dos trabalhadores, essa crença contribui para a manutenção de diferenças salariais entre os gêneros, uma vez que "a força de trabalho biologicamente apropriada para os empregos com salários mais altos”, que envolvem tal exposição, será compreendida como a masculina. De igual forma, tais políticas colocam a mulher em uma situação delicada uma vez que seus interesses como trabalhadora podem ser

casos de angiosarcoma, um tipo de câncer do fígado, assim como câncer em outros órgãos, entre trabalhadores da indústria de PVC. aumenta as chances de câncer de pulmão. Ver: BARROS, Fernando de. PVC um mal desnecessário. Master Ambiental. 4 de abril, 2012. Disponível em: < https://www.master ambiental.com.br/noticias/residuos-da-construcao-civil/pvc-um-mal-desnecessario/>. No ano de 2005, a Cetesb (agência ambiental paulista) encontrou altas concentrações de cloreto de vinila (47 vezes o limite permitido pelo ministério da saúde) em sete poços artesianos instalados na região de Santo Amaro, zona sul de São Paulo. Parte do aqǘfero (reservatório de água subterrânea) da região, entre as pontes Interlagos e do Socorro, está contaminado com solventes clorados, substâncias utilizadas na fabricação de plástico e também para lustrar metais. Informação em disponível em: BASSETE, Fernanda. Ambiente Degradado. Folha de São Paulo. Cotidiano, 22 de agosto de 2005. Disponível em: <https://www1.folha.uol.com.br/fsp/cotidian/ ff2 20820 0516.htm>

PRACS: Revista Eletrônica de Humanidades do Curso de Ciências Sociais da UNIFAP https://periodicos.unifap.br/index.php/pracs ISSN 1984-4352 Macapá, v. 12, n. 1, p. 123-143, jan./jun. 2019 
vistos como contrários aos interesses maternos.

Reduzir produtos químicos nocivos nos ambientes de trabalho, meio ambiente, objetos e processo de produção e distribuição de alimentos é uma maneira de combater não apenas a infertilidade, mas o desenvolvimento de inúmeras doenças. De igual forma, essa é uma prática que beneficiaria os mais diversos grupos de uma mesma realidade social e não apenas aqueles que podem pagar pelos "tratamentos de infertilidade".

Diante do que foi apontado até aqui, a escolha de uma "cura" para a infertilidade com características invasivas, cara, pouco confiável e acessível apenas a um certo grupo (como é o caso da fertilização in vitro) não parece razoável. No entanto, se a intenção das pesquisas era outra (obter notoriedade ou lucro, alterar as características de parte da população etc.), a insistência nelas faz mais sentido.

De qualquer maneira, como observa Arditti,

(...) uma verdadeira indústria da infertilidade foi desenvolvida para promover e comercializar as novas tecnologias reprodutivas: IVF [fertilização in vitro], bancos de esperma; empresas de sub-rogação; empresas farmacêuticas e empresas de instrumentalização científica especializadas nos instrumentos usados nos processos. Essa indústria determina o que é pesquisa "apropriada" com base no que será mais rentável para as vendas. (ARDITTI, 1997, p. 322)

O saber bio-tecno-científico oriundo dessas pesquisas aliou-se, nas últimas décadas, ao conhecimento produzido no campo da biologia molecular e da engenharia genética. A linguagem inicial (de "tratamento da infertilidade"), perdeu a força e têm ficado mais evidente o ideal eugênico de muitas pesquisas: aperfeiçoar certas qualidades humanas (eugenia positiva) e reduzir ao mínimo doenças e imperfeições (eugenia negativa). Esta engenética "se ocuparia da prevenção e cura de doenças e malformações consideradas de origem genética, com ações de caráter restritivo, diretamente sobre o patrimônio genético do indivíduo" (MAI e ANGERAMI, 2006, p. 255). De igual forma, ela também se encarregaria de melhorar características físicas e competências humanas (como inteligência, memória, criatividade artística, traços de caráter etc.).

O tipo de biopolítica que toma forma nas tecnologias reprodutivas aliadas a eugenética tem por objetivo a gestão das qualidades da população, mas inclui tentativas de desenvolver e maximizar metas para os mercados farmacêuticos, bem como outras formas de intervenção médica que alegam maximizar a qualidade de vida. Na maioria dessas práticas, a busca por óvulos para a produção de embriões segue em frente (junto com os processos de super-ovulação e retirada de parte do estoque natural de óvulos da "doadora").

Como observou Ana Reis (2012), a descoberta das células-tronco e de que elas não existem apenas nos embriões, mas no corpo inteiro, poderia significar uma mudança de rumo. No entanto, o novo discurso é o de que apenas as células-tronco embrionárias são totipotentes, (capazes de ser transformar em qualquer tecido-órgão). De igual forma, apesar delas terem, aparentemente, um grande potencial, faz muitos anos que se está pesquisando e os resultados não são tão espetaculares. Os sucessos e as possibilidades são sempre anunciados de maneira propagandística, espetacular (como ocorreu com as clínicas que buscavam captar mulheres para a pesquisa da fertilização in vitro), com a expectativas de obter dinheiro (e cobaias) para as pesquisas.

PRACS: Revista Eletrônica de Humanidades do Curso de Ciências Sociais da UNIFAP 
Há fortes interesses empresariais e econômicos atrás das pesquisas com células-tronco por conta das suas possíveis técnicas de reparação de tecidos e órgãos. Se essas técnicas forem patenteadas, por exemplo, a empresa ou país que conseguir patenteá-las acrescentarão à sua economia, nas palavras de um especialista, “o equivalente a um campo petrolífero!”. Ao que pergunta Ana Reis (2012) (e me junto a ela): “As mulheres serão postas a fabricar esse petróleo?”

\section{CONCLUSÃO}

Se a grandeza e a riqueza de uma nação está atrelada à quantidade e à qualidade de sua gente, do ponto de vista da biopolítica, as capacidades reprodutivas das mulheres tornam-se centrais. São responsáveis pela produção de trabalhadores, soldados, consumidores e, mais recentemente, embriões para pesquisas. Focar nas questões reprodutivas como se fossem unicamente coisa de mulher é, igualmente, parte importante de um projeto biopolítico, uma vez que permite colocar sobre as mulheres um conjunto de responsabilidades capaz de convencêlas a se subjugarem aos mais variados projetos e práticas, por mais invasivos, experimentais e insalubres que sejam.

A biopolítica, que encara questões de população como um problema biológico (científico) e, ao mesmo tempo, de relações de poder (político) pode obter das tecnologias reprodutivas maneiras cada vez mais precisas de controle. Para tanto, possui à sua disposição um conjunto de conhecimentos sobre cada fase do processo reprodutivo feminino, adquiridos por meio de experimentação científica levada a cabo no último século.

Embora ligasse a biopolítica aos esforços reguladores de Estados nascentes, Foucault reconheceu haver uma gama de instituições sub-estatais, como as instituições médicas, agindo no mesmo sentido regulatório. Nesse sentido, a medicalização dos corpos têm aumentado significativamente nos últimos cinquenta anos, em uma forte parceria entre pesquisadores, empresas (farmacêuticas ou mas) e poder estatal (que mantém a lei da livre concorrência funcionando e "fecha os olhos" para questões raciais ou de gênero em funcionamento nessas pesquisas). O exemplo mais exitoso dessa parceria é o uso cotidiano de medicação contraceptiva por milhares e milhares de mulheres em todo o mundo.

O poder de uma classe média branca e masculina sobre a biopolítica é perceptível desde os primeiros experimentos com tecnologias reprodutivas. De início, a forte crença no poder da hereditariedade levou à defesa desses experimentos por parte de grupos eugenistas interessados em "melhorar a nação" incrementando os nascimentos de crianças brancas "saudáveis e inteligentes" ao mesmo tempo que sugeriam a esterilização de grupos de imigrantes, negros e pobres. Com o avanço da engenharia genética, cada vez mais essa "tecnologia reprodutiva" tem dado lugar a uma "tecnologia do aprimoramento" que, por sua vez, segue com suas características classistas, racistas, capacitistas e sexistas, ainda que procure omiti-las.

A aceitação geral e a veneração pelo conhecimento científico, permitiu que determinados grupos de pesquisadores investissem em projetos que prometiam maior controle sobre os processos reprodutivos. Os avanços dessa biotecnologia não se deram de maneira semelhante sobre homens e mulheres. Em meio a uma cultura acostumada a pensar os machos da espécie como capazes de transcender o nível do biológico por meio do uso de suas faculdades racionais e as mulheres como incapazes dessa transcendência (presas à biologia de seus corpos e fadadas à reprodução e à maternidade), todo um campo de pesquisas se formou utilizando-se 
do corpo da mulher como material de experimentação.

As técnicas de um biopoder de controle social aparentemente benevolente, mas peculiarmente invasivas, foram se estabelecendo no campo da reprodução. O trinômio poder-saberverdade, apontado por Foucault em grande parte de suas obras foi se materializando nessas práticas. Novos conhecimentos foram estabelecidos ao lado de novas verdades e novas formas de atuar, visando a superação de certos defeitos encontrados nos corpos dos indivíduos (como a infertilidade e a ausência de características desejáveis para a próxima geração).

Apesar da realidade social ter se modificado consideravelmente e os mais diversos grupos de mulheres (na maioria feministas) terem lutado para modificar o estatuto ontológico e jurídico das mulheres (transformando-as em sujeitos racionais e com direitos), os corpos femininos seguem sendo reivindicados para a pesquisa genético-reprodutiva. A "captação de óvulos" e o implante de embriões não têm previsão de diminuir. Pelo contrário, pesquisadores seguem vendo o corpo feminino como mais ricos em matérias-primas, uma vez que possuem mais tecidos reprodutivos (como óvulos, em alta demanda em biotecnologias e pesquisas com células-tronco embrionárias).

A legislação relativa aos direitos de paternidade envolvida nas práticas de inseminação artificial alertam para o controle sempre renovado dos homens sobre os planos de mulheres que decidem ter suas famílias desafiando regras patriarcais. As mulheres costumam ter pouco poder sobre o que é considerado legítimo ou ilegítimo, legal ou ilegal, crime ou não-crime, nas práticas reprodutivas.

Dado a forte ênfase nas mulheres como principais responsáveis pela reprodução humana, ao longo de todo o processo de desenvolvimento das técnicas reprodutivas, é possível imaginar que segue sendo possível produzir um fenômeno de mobilização geral de mulheres para salvar as nações de seus baixos índices de natalidade, em momentos de crise. Tal realidade pode estar mais perto do que imaginamos.

Os índices mundiais de fertilidade têm baixado década após década. Segundo um relatório do Departamento de Assuntos Econômicos e Sociais da ONU (2013), um envelhecimento da população sem precedentes e sem paralelo na história está ocorrendo. Trata-se de um fenômeno generalizado, global, duradouro e com implicações profundas para muitas facetas da vida humana (econômica, política,. Religiosa, social...). A previsão é de que, por volta de 2050, o mundo poderá ser, pela primeira vez, mais idoso do que jovem (UNITED NATIONS, 2013). Além disso, os pontos do planeta e as taxas demográficas internas de países como o Brasil e o EUA apontam para o fato de que os grupos com índices de fertilidade mais elevado são justamente aqueles historicamente considerados indesejáveis pelas elites brancas.18

O enfrentamento de um largo conjunto de causas da infertilidade, associadas aos ambientes de trabalho, aos produtos comercializados pelas sociedades industrializadas, à poluição do meio ambiente, aos tipos de vida que restam como opção aos mais variados grupos vivendo nas grandes cidades, não parece ser interesse dos chamados grupos dominantes. Ainda que isso possa representar uma melhoria na saúde geral da população, a biopolítica contemporânea está por demais vinculada ao capitalismo e suas práticas, como já alertara Foucault no final da década de 1970.

Outro aspecto atrelado à baixa dos índices de "fertilidade" mundiais tem a ver com a reação

18 No Brasil, Norte e Nordeste apresentam o maior indice de natalidade em meio à uma população negra, parda, de menor poder aquisitivo (pobre) e menos instruidas. Nos EUA, são as hispânicas que lideram as taxas de fecundidade. No globo terrestre, esse lugar é ocupado por paises africanos e asiáticos. (GALLAGHER, 2018)

PRACS: Revista Eletrônica de Humanidades do Curso de Ciências Sociais da UNIFAP https://periodicos.unifap.br/index.php/pracs ISSN 1984-4352 Macapá, v. 12, n. 1, p. 123-143, jan./jun. 2019 
das mulheres ao modelo de sociedade estabelecido. Gerar crianças, para milhares de mulheres, não é um projeto aceitável quando todas as atividades de cuidado recaem apenas sobre elas. Mulheres que têm refletido sobre essa questão e que têm podido investir em outros projetos de vida, diminuíram drasticamente o número de filhos.

A má distribuição das tarefas reprodutivas atreladas ao cuidado das crianças, raríssimas vezes entram em pauta em sociedades controladas por homens (patriarcais). O mesmo pode ser dito sobre as modificações necessárias no mercado de trabalho para acomodar as expectativas de homens e mulheres que se dispõem a assumir a tarefa de investir no cuidado de crianças por todo o tempo necessário (um investimento que ultrapassa uma década de vida, dado o elevado grau de dependência de qualquer ser humano nas fases iniciais de sua vida).

Ainda precisamos desenvolver ferramentas conceituais para a análise crítica das relações entre biopolítica, biotecnologia e bioeconomia. Enquanto isso, a realidade social apresenta mostras de resistência. Em uma era que promete enorme expansão do controle sobre nossos processos biológicos, a teoria democrática liberal, os projetos comunitários e socialistas, os feminismos, as lutas dos grupos organizados de deficientes, os movimentos LGBTTs atuam em uma verdadeira contra-mão, valorizando as diferenças e opondo-se a normas supostamente biológicas e biologizantes.

\section{REFERÊNCIAS}

ANDERSON, Lisa. The Infertility Crisis. Chicago Tribune, 11 de dezembro de 1985. Disponível em: <https://www.chicagotribune.com/news/ct-xpm-1985-12-11-8503250606story.html>. Acesso em: dezembro de 2018.

ANDREWS, Lori B. The Clone Age. Adventures in the New World of Reproductive Technology. Cap. 1. New York: Henry Holt \& Company, 1999. Disponível em: <https://archive.nytimes.com/www.nytimes.com/books/first/a/andrews-clone.html> . Acesso em: dezembro de 2019.

ARDITTI, Rita. Commercializing Motherhood. In: JETTER, Alexis; ORLECK, Annelise e TAYLOR, Diana (eds.) The Politics of Motherhood: Activist Voices from Left to Right. Hanover: University Press of New England, p. 322-333, 1997.

CAPUANO, Christophe. La construction des politiques natalistes et familiales durant l'entre -deux-guerres: modèles et débatstransnationaux". Revue d'Histoire de la Protection Sociale, vol. 1, no 5, p. 31-45, 2012. Disponível em: <https://www.cairn.info/revue-d-histoire-dela-protection-sociale-2012-1-page-31.htm>. Acesso em: janeiro de 2019.

CASTRO, Edgardo. E1 vocabulario de Foucault. Un recorrido alfabético por sus temas, conceptos y autores. Buenos Aires: Prometeu/Universidad Nacional de Quilmes, 2004.

COREA, Gena. The Mothering Machine. Reproductive Technologies from artificial Insemination to artificial wombs. New York: Harper \& Row 1985.

CORREA, Marilena C. D. V; LOYOLA, Maria Andrea. Tecnologias de reprodução assistida no Brasil: opções para ampliar o acesso. Physis Revista de Saúde Coletiva, Rio de Janeiro, vol. 25, no 3, p. 753-777, 2015.

DRAPER, E. Fetal Exclusion Policies and Gendered Constructions of Suitable Work, Social Problems, vol. 40, no 1, Fevereiro de 1993.

FOUCAULT, Michel. Nascimento da Biopolítica, São Paulo: Martins Fontes, 2008.

. Em Defesa da Sociedade. Curso no Collège de France (1975-1976). São Paulo: 
Martins Fontes, 2005.

. Historia da sexualidade 2: o uso dos prazeres. Rio de Janeiro: Graal, 1984.

HYNES P. H. The Recurring Silent Spring, Oxford: Pergamon Press, 1989.

IPSEN, Carl. Dictating demography. The problem of population in Fascist Italy, Cambridge: Cambridge University Press, 1996.

MAI, Lilian Denise e ANGERAI, Emília Luigia Saporitiai. Eugenia negativa e positiva: significados e contradições. Revista Latino-americana de Enfermagem, vol. 14, n 2, p. 251258, março-abril de 2006.

MASON, M. C. Infertility: The Problem with Sperm. Everywoman, February 1993.

MASSEY JR, Albert P. Artificial Insemination: The Law's Illegitimate Child. Villanova Law

Review, vol. 9, n¹, 1963. Disponível em: <http://digitalcommons.law.villanova.edu/vlr/ vol9/iss1/6>. Acesso em: novembro de 2018.

MCLAUGHLIN, Loreta. The Pill, John Rock, and the Church. The Biography of a Revolution. Boston/Tronto: Little, Brown \& Company, 1982.

MORAES, Maria Simone de; ANDRADE, Asmar de. Obesidade e Infertilidade na Reprodução Humana Assistida. Revisão Bibliográfica. Pontífica Universidade Católica de Goiás, s/d. Disponível em: <http://www.cpgls.pucgoias.edu.br/6mostra/artigos/BIOLOGI CAS/MARIA\%20SIMONE\%20DE\%20MORAES.pdf>. Acesso em: fevereiro de 2019.

NETO, Leon Fahri. Biopolítica como tecnologia de poder. Interthesis. Revista Internacional Interdisciplinar, v. 5, no 1, 2008.

NICOLOPOULOS-STAMATI, P. e PITSOS, M.A. The impact of endocrine disruptors on the female reproductive system. Human Reproduction Update. vol .7, no 3, p. 323-330, 2001.

QUEEN'S University. Common Industrial Chemical Now Linked To Male Infertility; Chemical Adversely Affects The Normal Development Of Sperm. ScienceDaily. 7 de março de 2003. Disponível em: <www.sciencedaily.com/releases/2003/03/030307071845.htm>. Acesso em: março de 2019.

RABINOW, Paul e ROSE, Nikolas. Foucault Today. In: The essential Foucault: Selections from the essential work of Foucault, 1954-1984. New York: New Press, Junho 2003. p. viixxxv. Disponível em: <http://kenrogers.org/archive/items/show/100>. Acesso em: 27 fevereiro, 2011.

RABINOW, Paul e ROSE, Nikolas. Le bio-pouvoir aujourd'hui. Raison Publique, Sessão Études, 12 de maio de 2012. Disponível em: < http://www.raison-publique.fr/article536.html $>$. Acesso em: outubro de 2018. (originalmente publicado sob o título "Biopower Today", BioSocieties, no1, 2006, p.195-217).

REDDY, B.S. et al. Association of phthalate esters with endometriosis in Indian women. BJOG. Vol. 113, no 5, p. 515-520, 2006.

REIS, Ana. Entrevista: Pesquisadora aborda ricos da reprodução assistida para a mulher. Vermelho. 10 de junho de 2012. Disponível em: <http://www.vermelho.org.br/noticia _print.php?id_noticia=185066\&id_secao=10>. Acesso em fevereiro de 2019.

SCOTT, J.A. Keeping Women in Their Place: Exclusionary Policies and Reproduction. In: Chavkin, W. Double Exposure: Women's Health Hazards on the Job and at Home. Monthly Review Press, New York, 1984.

SEXTON, Sarah. The Reproductive Hazards of Industrial Chemicals. The Politics of Protection. The Corner House. nov. 1993. Disponível em: <http://www.thecornerhouse.org. 
uk/resource/reproductive-hazards-industrial-chemicals\#fn055ref $>$.Acesso em: março de 2019.

STEPTOE, Patrick e EDWARDS, R. G. Reimplantation of a human embryo with subsequent tubal pregnancy. The Lancet, vol. 307, no 7965, p. 880-882, 1976. Disponível em: <https://kundoc.com/pdf-reimplantation-of-a-human-embryo-with-subsequent-tubal-pregnancy-.html>. Acesso em: dezembro de 2018.

THÉBAUD, Franç,oise. Le mouvement nataliste dans la France de l'Entre-deux-guerres: l'Alliance nationale pour l'accroissement de la population française. Revue d'histoire moderne et contemporaine, no 32, p. 267-301, 1985.

UNITED NATIONS, World Population Ageing 2013. Department of Economic and Social Affairs of the United States, Population Division, 2013. Disponível em: <http://www.un.org/en/development/desa/population/publications/pdf/ageing/WorldPopulationAgeing2013.pdf>. Acesso em: maio de 2014.

WEYRATHER, Irmgard. Mutterkreuz und Muttertag. Der Kult um die deutsche Mutter im Nationalsozialismus, Frankfurt/Main, 1993. 